\title{
Youth participation and agency in the United Nations Framework Convention on Climate Change
}

\author{
Harriet Thew ${ }^{1}$ (D)
}

Accepted: 13 February 2018 / Published online: 23 February 2018

(C) The Author(s) 2018. This article is an open access publication

\begin{abstract}
This article examines the participation and agency of young non-state actors (NSAs) in the United Nations Framework Convention on Climate Change (UNFCCC). It utilizes the constituency of Youth NGOs: YOUNGO, as a case study to examine the relationship between selection of participatory strategies, power sources (following Nasiritousi et al. in Int Environ Agreem Politics Law Econ 16(1):109-126, 2016), recognition and agency using ego and alter perceptions. It finds that young people's selection of participatory strategies and power sources is shaped by the level of agency which they perceive to be available to them. When self-perception of agency is high, young participants offer constructive policy amendments which can lead to recognition and agency, though only within certain policy areas and the silos in which they are negotiated. When self-perception of agency is low, youth interpret this as lack of recognition, leading to efforts to assert their relevance and/or to challenge procedural legitimacy: neither of which are well received by decision-makers. In reality, several of the challenges faced by young participants are not structurally unique to their constituency; however, their lack of financial resources does hinder their ability to fully utilize modes of participation which previous studies have found to be beneficial to other NSAs, such as side-events. Financial constraints also restrict the ability of youth participants, many of whom are volunteers, to develop professional relationships with key actors over time, meaning that the level of agency developed by more established, better-resourced NSAs remains largely out of reach. These findings have implications for the understanding of NSA agency, which has previously been treated as homogeneous and raises further questions regarding procedural legitimacy of the UNF$\mathrm{CCC}$ and its role in mobilizing and empowering the next generation.
\end{abstract}

Keywords Agency · Youth · Participation - UNFCCC · Non-state actors · Power sources · Climate Change $\cdot$ Governance

Harriet Thew

H.Thew@Leeds.ac.uk

1 Sustainability Research Institute, School of Earth and Environment, University of Leeds, Leeds LS2 9JT, UK 


\section{Introduction}

The modern world is faced with global environmental challenges of unprecedented proportions. In response, governments around the world have recognized the importance of cooperation, seeking mutually acceptable solutions for the protection of the planet and its people. Reaching consensus and initiating state-led action has proven difficult, with increased recognition that multi-actor solutions are required to supplement limited governmental resources (Albin 1999). As a result, the number and diversity of Non-state actors (NSAs) in global environmental governance is growing and their role is becoming increasingly broad (Albin 1999; Bulkeley and Newell 2015). In recognition of this, many intergovernmental processes are encouraging NSA participation, as reiterated in the outcome documents of recent, landmark environmental conferences including Rio+20 and UNFCCC COP 21 (United Nations 2012; UNFCCC 2015). As we enter a new, Post-Paris era of climate governance, seeking to foster a collaborative, multi-actor approach (Jordan et al. 2015) it is important to assess the level of agency which NSAs possess in the UNF$\mathrm{CCC}$, which retains a central role. Previous studies have attempted this, though despite acknowledgement that NSAs are not homogenous, they have focused primarily on larger, more established groups and, consequently, the agency of smaller, less dominant NSAs is not well understood.

This paper focuses on youth participation in the United Nations Framework Convention on Climate Change (UNFCCC). Although recognized as an independent stakeholder by Agenda 21 in the 1992 Rio 'Earth Summit' which established the UNFCCC (UNCED 1992), youth were not officially recognized within climate governance for another seventeen years, gaining constituency status as Youth NGOs or 'YOUNGO' in 2009 (UNFCCC 2010). Existing literature makes little distinction between different types of NSAs and their agency, largely treating them as homogenous, with the exception of Heike Schroeder's study on Indigenous People's Organizations (Schroeder 2010). As such, the study of youth participation and agency is uncharted territory offering significant potential to increase understanding of how agency is experienced differently by heterogeneous NSAs. In the current era of climate governance where NSA participation is seen to be increasingly necessary (Jordan et al. 2015), exploring the diverse participatory experiences of diverse NSAs is a critical and timely consideration. As the closest living relatives to the 'future generations' which the UNFCCC seeks to protect, nominal representatives of over $50 \%$ of the global population and the generation who will not only be most impacted by climate change but who will also inherit responsibility for tackling it, the participation and agency of youth is a particularly pertinent concern.

This paper introduces YOUNGO, providing an overview of its membership and structure based on the author's participation in and observation of the constituency over a six year period. A literature review follows, situating this study within existing research on NSA agency in global environmental governance. The qualitative methodological approach taken is then explained, before results are presented, structured around modes of participation available to UNFCCC constituencies and utilized by YOUNGO (conference access, plenary interventions, high-level meetings, actions, side-events and exhibits). These are explored firstly from a youth perspective and secondly from the perspectives of the decision-makers they seek to influence. Following Nasiritousi et al. (2016), the concept of 'power sources' is used to assess the sources of authority which youth participants draw upon in attempt to increase their agency. 
Findings demonstrate that youth utilize all of the modes of participation facilitated for them by the UNFCCC, though their ability to fully engage with them is dictated by availability of certain power sources, indicating that the potential for agency is not equally available to all NSAs in the UNFCCC. The study finds that youth select power sources based on the level of recognition and agency they perceive to be offered by any given participatory opportunity. State Actor perceptions indicate that certain power sources and strategies do not always have the desired response.

\section{Non-state actor agency in global environmental governance}

\subsection{Youth participation in the UNFCCC}

Youth have shown an interest in the UNFCCC since its inception, initially holding external conferences and presenting declarations to the Conferences of the Parties (COPs) before formally registering with the UNFCCC, forming delegations to participate directly, uniting to advocate on behalf of youth and eventually gaining constituency status (UNFCCC 2010). Membership is open to all, with neither fees nor commitment required, though based on a loose understanding that constituents are under 30 years old. Under-eighteens were only permitted to attend COPs for one day a year, on 'Young and Future Generations Day', until rules were changed in 2017 extending access to sixteen and seventeen year olds, though younger children can participate in online discussions and external events throughout the year. YOUNGO can be seen as a Transnational Advocacy Network (TAN) operating within the UNFCCC. Similarly to other TANs, it brings together large transnationals with small voluntary organizations, uniting moderate and more radical 'insiders' and 'outsiders' (Rodrigues 2003). The constituency consists of over forty accredited organizations, based in over twenty countries (UNFCCC 2014a). These range from small, voluntary groups such as the UK Youth Climate Coalition and Indian Youth Climate Network to large international youth organizations such as the World Organization of the Scouting Movement. Additionally, a handful of governmental delegations, including the Netherlands and Belgium, have established official youth delegate programs whose participants often choose to work with YOUNGO.

YOUNGO annually elects two Focal Points through an online voting system. Equitable representation is a normative concern, addressed, partially, with appointment of a Global North and Global South Focal Point who take responsibility for liaison with the UNFCCC Secretariat but are unpaid and have no leadership mandate. As the majority of YOUNGOs are volunteers, investing their own time and money, turnover is high as repeat attendance is costly. Unless they secure employment or sponsorship, most youth are unable to maintain long-term engagement. Financial support often comes with obligations to another constituency, so although several young people are recruited to work for Environmental NGOs, UN institutions or governmental delegations, those who remain YOUNGOs are predominantly unpaid. Global South youth have particular difficulties in obtaining funding and visas and therefore, in spite of a desire to be more representative, the spokespeople for international youth within the UNFCCC usually come from fairly privileged backgrounds.

YOUNGOs have established approximately twelve policy working groups since gaining constituency status, advocating on issues including adaptation and the UNFCCC's Article 6 on climate change education, training, public participation, public access to information 
and public awareness, recently rebranded as Action for Climate Empowerment, known as "ACE". Working Groups rely upon volunteers to maintain activity during and between conferences, creating challenges in sustaining relationships with decision-makers and retaining institutional memory. YOUNGOs are bound by the rules of observer participation, able to watch but not participate in negotiations and granted the same participatory opportunities as other constituencies. However, their participatory strategies and the level of agency they possess is not yet understood, which this paper seeks to remedy.

Global environmental governance can occur without NSAs, though several multilateral processes have elected to include them, creating new modes of participation to support their involvement (Steffek and Nanz 2008). This is attributable to changing perceptions of legitimacy, as belief in absolute state sovereignty has fallen out of fashion (Keck and Sikkink 1999). Nevertheless, State Actors (SAs) retain the mandate and thus the authority for decision-making within the intergovernmental process, so NSAs seek to convince SAs to share or transfer agency to them for the performance of certain tasks (Albin 1999; Dellas et al. 2011).

This paper follows (Dellas et al. 2011; Nasiritousi et al. 2016), differentiating between actors who have the ability to participate in intergovernmental meetings and agents who have the ability to influence the outcome of these events. Agency can be understood in relation to the governance activities which a particular group of NSAs has gained recognition for their potential to perform, as further explained below.

\subsection{Transnational advocacy networks and modifications}

NSAs possess varying levels of resource, capacity and skill, with better-resourced, betternetworked organizations tending to dominate (Albin 1999; Boström and Hallström 2010). To increase their agency, many NSAs unite in Transnational Advocacy Networks (TANs) (Keck and Sikkink 1999) which span international borders. They share knowledge and resources, advocating on shared values, with diverse members shaping and being shaped by these networks. As NSAs, they lack the mandate to create intergovernmental policy and must therefore frame their knowledge to appeal to state actors. Their advocacy takes distinct forms as identified in Keck and Sikkink's (1999, p. 95) four part typology:

(a) Information politics, or the ability to move politically usable information quickly and credibly to where it will have the most impact.

(b) Symbolic politics, or the ability to call upon symbols, actions or stories that make sense of a situation or claim for an audience that is frequently far away.

(c) Leverage politics, or the ability to call upon powerful actors to affect a situation where weaker members of a network are unlikely to have influence; and

(d) Accountability politics, or the effort to oblige more powerful actors to act on vaguer policies or principles they formally endorsed.

Nasiritousi et al. (2016) modify this typology, combining it with an agency-focused study of environmental standard-setting (Boström and Hallström 2010), to identify five 'power sources' which NSAs draw upon, utilizing their knowledge, membership and resources to acquire agency. NSAs are said to have Cognitive Power when they hold relevant information and have sufficient understanding of a policy process to know when and where to present it. Leverage Power is held when NSAs have access to policy processes and can influence key agents within them, and the Symbolic Power of large membership 
numbers and/or perceived moral integrity which can be drawn upon to support their advocacy claims. Nasiritousi et al. (2016) add that NSAs also have Material Power, when they possess sufficient financial and material resources to support their advocacy efforts and Social Power when they have access to networks and the ability to be heard within them. This paper uses YOUNGO as a case study to test these five power sources, identifying the strategies employed by young people to wield them and exploring how youth choose between these power sources depending upon the level of agency which they perceive to possess in any given circumstance.

Nasiritousi et al. (2016) claim that NSAs use 'power sources' to gain agency based on recognition of their ability to perform certain activities which make up their 'Governance Profiles.' Following Albin (1999), they identify nine governance activities which NSAs can gain recognition for: influencing the agenda; proposing solutions; providing information; providing expertise; raising awareness; implementing action; evaluating consequences of policies and measures; representing public opinion and representing marginalized voices. These are then used to identify the Governance Profiles of NSA groups. Following Arts (1998), they state that agency can be understood using ego and alter perceptions to establish whether a group has gained recognition for their ability to perform these activities, by utilizing their 'power sources'. This understanding of agency, followed by this paper, is in line with previous studies, including Dellas et al. who claim that, for agency: 'the importance of recognition cannot be overstated.' (2011, p. 93). However, research has yet to assess how NSAs choose which power source to draw upon at any given time, which strategies they use to wield a particular power source and which combination of strategies and power sources is more likely to lead to recognition and agency.

\subsection{NSA participation in global climate change governance/UNFCCC}

Case-study research on NSAs in the UNFCCC predominantly focuses on the Environmental NGO (ENGO) and Business NGO (BINGO) constituencies (Betsill 2008; Gulbrandsen and Andresen 2004; Vormedal 2008). It therefore runs the risk of overstating NSA influence, as these constituencies are larger, more established, better resourced and potentially suffer less from collective action problems than other NSA groupings (Betsill 2008; Hanegraaff 2015). Betsill (2008) found that NSA influence is shaped by the nature of the issue being discussed (particularly in relation to how contentious it is and whether an NSA group has sufficient financial resource to counteract the influence of oppositional lobbyists) and that the level of technicality associated with a particular negotiation, perhaps unsurprisingly, shapes the level of technical expertise that NSAs need to engage with it. This suggests that having a range of power sources at their disposal is critical for NSA influence/ agency but that not all constituencies have equal reserves. Betsill calls for further research into whether the nature of an issue has implications for NSA influence and what the relationship looks like between NSA agency and their selection of participatory strategies. She also acknowledges the benefits of sustained participation over time, as illustrated by the ability of ENGOs to overcome restrictions to observer access (during the Kyoto Protocol negotiations) on account of having pre-established relationships with negotiators. This enabled them to gain an insider position from which to lobby from, remaining in contact via cell-phone to hear and comment on what was happening behind closed doors (Betsill and Corell 2008); a valuable route to influence which may not be open to all NSAs (Lövbrand et al. 2017). 
Schroeder and Lovell (2012) identify a series of ways in which NSAs can participate in the UNFCCC, from observing negotiations, and engaging in advocacy during informal meetings and social events; to more formalized modes of participation such as attending and hosting side-events and exhibits; giving plenary interventions; making written submissions; holding press conferences and making protests. However, little is known about which modes of participation NSAs favor and why, nor about the relationship between modes of participation, selection of power sources and the ability of smaller TANs to gain agency.

Quantitative research from Nasiritousi et al. (2016) compliments earlier case studies. In surveys at COP 17 and 18, they asked over 500 SAs and NSAs to select the constituency which they felt was most significant to the nine aforementioned governance activities. However, as participants were only able to select one constituency per activity, findings do not reflect that agency can be shared (Dellas et al. 2011) and even after emphasizing that attention be paid to smaller constituencies, the Women and Gender, Farmers and YOUNGO constituencies were excluded from their research due to space limitations.

Other studies have focused on particular modes of facilitated participation within the UNFCCC (Hjerpe and Linnér 2010; Hjerpe and Buhr 2014; Schroeder and Lovell 2012), with side-events receiving most attention on account of being deemed the 'most visible' form of NSA participation (Hjerpe and Linnér 2010). Hjerpe and Linnér identify 6 functions of side-events: building capacity; introducing potential items for negotiation; disseminating information; interconnecting people and policy areas; providing a forum for other levels of governance and legitimizing global governance, while Hjerpe and Buhr (2014) identify trends in the way in which climate change has been framed in UNFCCC sideevents. These studies suggests that side-events can be a vehicle for NSA agency as attendees benefit from access to up-to-date expertise and networking opportunities while hosts are able to introduce new ideas and to frame issues. Hjerpe and Linnér (2010) argue that side-events benefit the UNFCCC process by increasing perceived input legitimacy through seeming inclusion of a wide range of actors. Upon closer inspection, however, they identified a lack of diversity in side-event hosts (geographically and epistemologically speaking, they do not engage in age-based analysis) challenging the belief expressed by state actors in their study that side-events enhance pluralism. This suggests a need to explore how sideevents are perceived and utilized by less dominant NSA groups in the UNFCCC, such as youth.

Schroeder and Lovell (2012) suggest that NSAs engage in side-events in order to 'be visible and to raise their profile' (p. 31), indicating that side-events perform a clear function in increasing the recognition of NSAs engaged in them. Their study supports Hjerpe and Linnér's (2010) argument that side-events can indirectly introduce agenda items by acting as an incubator for new ideas, though this process is limited by lack of formal coordination between side-events and negotiations. Schroeder and Lovell (2012) also propose that the type of NSA hosting the side-event plays a role in the extent to which they interact with the negotiations, suggesting a potential difference in the ability of different NSAs to utilize side-events to increase their agency, though this remains unexplored.

\section{Methodology}

Data collection consisted of twenty-three semi-structured interviews, a focus group with sixteen participants, and participant observation during the 40th Intersessional of the UNFCCC Subsidiary Bodies (SB40) in 2014. Ego and Alter perceptions (Arts 1998) were used 
to compare YOUNGO's self-perception (ego) with how negotiators and Intergovernmental Organizations perceive them (alter), to assess whether recognition is attained. NSA participation at Intersessionals is smaller and less geographically diverse so data collection at a COP would have been preferable, though all interviewees had attended previous COPs and Intersessionals and distinguished between the two types of conference when necessary. As a participant at five COPs and five intersessionals, the researcher was also able to draw upon personal experience to recognize any differences.

Youth participation at COP 21 was abnormal as a result of unusually high public interest which increased applications, curtailing quotas for regular participants. This, coupled with heightened security following Parisian terror attacks, resulted in an unprecedented number of negotiations being closed to observers, negatively affecting youth perceptions of participation. At SB44, the subsequent conference, there were lingering concerns expressed by NSAs, including youth, though discussions around Access to Intergovernmental Meetings suggested an imminent return to 'normal' participation. In recognition of this anomaly, only data from SB40 in 2014 were included in this study.

A balanced sample of alter perceptions were collected from seven Global South and seven Global North negotiators from the majority of UNFCCC negotiating blocks: the Least Developed Countries; African Group; Alliance of Small Island States; G77; European Union; Umbrella Group and the Environmental Integrity Group. The majority had substantial experience and responsibility, several had been participating over 5 years, a few for over ten, and two were Heads of Delegation.

In recognition that negotiators working on Article 6: the policy on public participation may have differing views to their colleagues on NSA involvement, interviews were sought with both Article 6 and non-Article 6 negotiators. YOUNGO have had a working group following Article 6/ACE since 2009 so it is an appropriate policy to analyze their agency. Article 6 and non-Article 6 interviewees were selected from the same delegations or negotiating blocks for direct comparison, to determine whether policy silos influence perceptions. Of the fourteen negotiators interviewed, six worked on Article 6 and eight did not, with equal Global North and South representation. Interviews were also conducted with three key informants from intergovernmental organizations, all working on Article 6. Interview classifications are shown in Table 1.

Ego perceptions were collected through six interviews with youth who had attended at least two previous UNFCCC negotiations where they had engaged with YOUNGO to ensure that they had sufficient experience of both UNFCCC participation and YOUNGO membership. Interview duration for both the ego and alter samples ranged from 25 to $50 \mathrm{~min}$. Interviews were transcribed and deposited into Nvivo for analysis. However, several participants refused to be recorded. In these instances, detailed notes were taken during and immediately after each interview which were later typed up and added to Nvivo.

To increase the ego sample and observe discussions between members regarding their participation, a focus group was also held with sixteen YOUNGOs. Additionally, YOUNGO daily meetings and youth participation in conference proceedings were observed for further triangulation to assess whether their behavior matched the responses they gave during interviews and focus groups.

A grounded approach was taken to generate theory (Charmaz 2014) in Nvivo with selective coding applied initially, based on power sources from the literature, e.g., 'Moral Power' and Participatory Opportunities within the UNFCCC, e.g., 'Interventions'. Open coding was used when new findings were identified and finally axial coding permitted identification of the relationships between participatory opportunities, power sources and agency. 
Table 1 Classification of interviewees

\begin{tabular}{|c|c|c|c|}
\hline Actor type & Representation & Policy focus & Code \\
\hline Negotiator & Global north & Article 6/ACE & A1 \\
\hline Negotiator & Global north & Article 6/ACE & A2 \\
\hline Negotiator & Global north & Article 6/ACE & A3 \\
\hline Negotiator & Global north & Article 6/ACE & A4 \\
\hline Negotiator & Global south & Article 6/ACE & A5 \\
\hline Negotiator & Global south & Article 6/ACE & A6 \\
\hline Negotiator & Global south & Non-article 6/ACE & B1 \\
\hline Negotiator & Global south & Non-article 6/ACE & $\mathrm{B} 2$ \\
\hline Negotiator & Global south & Non-article 6/ACE & B3 \\
\hline Negotiator & Global south & Non-article 6/ACE & B4 \\
\hline Negotiator & Global north & Non-article 6/ACE & B5 \\
\hline Negotiator & Global north & Non-article 6/ACE & B6 \\
\hline Negotiator & Global north & Non-article 6/ACE & B7 \\
\hline Negotiator & Global north & Non-article 6/ACE & B8 \\
\hline Intergovernmental & Global north & Article 6/ACE & $\mathrm{C} 1$ \\
\hline Intergovernmental & Global north & Article 6/ACE & $\mathrm{C} 2$ \\
\hline Intergovernmental & Global north & Article 6/ACE & $\mathrm{C} 3$ \\
\hline YOUNGO & Global north & Article 6/ACE & D1 \\
\hline YOUNGO & Global north & Article 6/ACE & D2 \\
\hline YOUNGO & Global north & Article 6/ACE & D3 \\
\hline YOUNGO & Global south & Non-article 6/ACE & E1 \\
\hline YOUNGO & Global north & Non-article 6/ACE & $\mathrm{E} 2$ \\
\hline YOUNGO & Global north & Non-article 6/ACE & E3 \\
\hline
\end{tabular}

\section{Results}

By cooperating as a TAN, youth have gained recognition from the UNFCCC Secretariat in the form of constituency status. In addition to having conference access, this offers them formal participatory opportunities, which this section explores in turn to consider how they are perceived and utilized by youth participants, and the implications of this for youth agency. Based on participant observation, the following modes of NSA participation in the UNFCCC have been identified: Access, Plenary Interventions, High-Level Meetings, Actions, Side-Events and Exhibits. ${ }^{1}$ These are considered from ego and alter perspectives to assess how each shapes youth participation and, which are more likely to lead to recognition, thus enabling transitions from actors to agents.

\subsection{Conference access}

Accreditation grants access to the conference, though several negotiations are closed due to political sensitivity or space limitations. When room capacity is limited, it is common that each constituency receives a small number of secondary passes. At SB40, YOUNGO were warned that these could be withdrawn if not utilized and pass holders were required to sign

\footnotetext{
1 Plenary Interventions, High-Level Meetings and Actions are only available to NSAs through registration with an official constituency.
} 
into confirm their attendance. However, they did not prioritize this, as it did not include a speaking role for them, which they perceived as a lack of recognition. ${ }^{2}$ One interviewee reported being last to be seated when observing a negotiation of the Ad Hoc Durban Platform for Enhanced Action with a secondary pass, saying that she had been: 'treated like a second class citizen." ${ }^{3}$ There is a danger that in rejecting opportunities to witness key discussions it could limit YOUNGO's ability to wield Cognitive Power by diminishing their understanding of the negotiations.

Some YOUNGOs focus on specific policy areas where they perceive to have Cognitive Power. At SB40, YOUNGO's most active policy working group followed Article 6, perceived as particularly open to youth input:

Article 6 is a good place for youth influence, youth can really help (Interview D2).

They developed relationships with Article 6 negotiators, gaining Leverage Power which led to a closed negotiation being opened to observers. As such, they see Article 6 negotiators as allies:

People who work on Article 6 are all friends. They all want the same thing (Interview D1).

They also perceive that they have a role in its implementation:

I've been following Article 6 as that is something we can act on (Focus Group Participant)

YOUNGO's Cognitive and Social Powers are officially acknowledged with in-session speaking opportunities to share their experiences of education, participation and awareness-raising (often focused on social media) in annual 'Dialogues', mandated by the 2012 Doha Work Programme on Article 6. Here YOUNGO draws upon Cognitive Power to increase their agency as policy-making advisors and offers Social Power to support awareness-raising efforts.

All non-youth interviewees were aware that youth have constituency status, which they invariably claimed to be important. They stated that youth participation was crucial for procedural legitimacy ${ }^{4}$ and longevity, referring to the constituency's Symbolic Power as the representatives of young and future generations. ${ }^{5}$ However, this may have been influenced by researcher positionality, as this was expressed in personal terms:

It is good for you to be here, I will die and you will take over (Interview B7).

It is your future not ours (Interview B4).

In spite of this, several negotiators failed to acknowledge any additional value to be gained by engaging with youth, ${ }^{6}$ highlighting that Symbolic Power may be less likely to lead to agency, as seen in this interaction:

Researcher: Have you noticed any youth participants here? Negotiator: Not really but it is worth them coming. I saw youth make a comment in plenary but I couldn't listen (Interview B7).

\footnotetext{
${ }^{2}$ Focus Group.

${ }^{3}$ Interview E1.

${ }^{4}$ Interviews A1; A3; B7.

5 Interviews: A3; A4; B4.

${ }^{6}$ Interviews B4; B5; B7.
} 
Some negotiators referred to a need to reach a global climate agreement for, but not with young people ${ }^{7}$ expressing well-meaning sentiments which failed to acknowledge that youth could play an active role:

I have children; I know we need to do more (Interview B6).

The value of face to face contact was expressed by one, highlighting that the strategies employed by YOUNGO affect alter perceptions and, in turn, youth agency.

Researcher: Have you been influenced by youth in this process?

Negotiator: No but they have never tried to talk to me (Interview B3).

Those who did recognize an active role for youth described this primarily in relation to their Cognitive Power, ${ }^{8}$ as emphasized by Article 6 negotiators:

An innovative youth movement will always have an impact, we expect new ideas from them (Interview A3).

A lot of negotiators have been doing this for 20 years. They aren't adding anything new (Interview A4).

As perceived by the young participants, decision-makers recognized their Cognitive Power in relation to Article 6 policy, which youth have successfully wielded by offering incremental policy amendments. This includes recognition from IGO representatives as demonstrated in the following quote:

Having heard the youth statements and seen connections in the text I think it is safe to assume that youth influence on Article 6 was adopted by the COP (Interview C1).

This sentiment was shared by negotiators working on Article 6, who emphasized that youth have made specific policy inputs while their ongoing interest in the topic has contributed to keeping these issues 'alive', i.e. on the negotiating table.

In an area where I didn't have a firm view, a good suggestion from YOUNGO about the Doha Work Programme influenced my position and we have that now (Interview A1).

In some issues, we see more references to and from YOUNGO in the text, especially on Article 6. Article 6 is still alive partly because of YOUNGO (Interview A2).

Relationships developed over time have led to recognition of individuals and the constituency:

[Name removed] is a good lobbyist. He came to see us with clear suggestions 2 or 3 years in a row. The points he made today [listed each point] were very helpful, we will take them on board (Interview A3).

Youth can really have an influence, like today in the Dialogue. Some of their messages were very focused, like the one about involving psychologists to create behavioral change (Interview A5).

These quotes emphasize YOUNGO's use of Cognitive Power, rather than any other power source, suggesting that it is their collaborative input rather than their youth which has led to recognition in this policy area. It could be that negotiators who work on the policy on

\footnotetext{
7 Interviews: B4; B6; B7.

${ }^{8}$ Interviews A1; A2; A3; A4; A5; B1; B2; C1.
} 
public participation are predisposed to be more open to youth suggestions. There were two anomalies to this hypothesis: Interviewee A6 did not recognize YOUNGO's contribution. On further investigation, it was discovered that while she had been negotiating on the Kyoto Protocol (the subject of many YOUNGO actions and interventions) for 3 years, she had only been assigned to Article 6 for SB40. The other anomaly was Interviewee B8. She spoke positively of youth participation and was aware of many YOUNGO advocacy messages. She negotiated on mitigation and stated that youth had never spoken to her directly about this. However, during post-interview discussion, it transpired that she had previously worked on Article 6 for a couple of years. This further corroborates the evidence that it is through positive engagement with YOUNGOs working on Article 6 over time, that alter perceptions have improved, increasing recognition. However, as policies are negotiated in silos, this recognition only extends as far as the decision-makers who are directly involved, so YOUNGO's agency in other policy areas remains low.

\subsection{Plenary interventions}

YOUNGO's plenary interventions often draw upon the Cognitive Power of others, rather than offering suggestions based on their own experiences. Youth often use interventions to demonstrate their familiarity with academic material such as IPCC reports. This is regularly combined with Symbolic Power, strategically wielded using both representative and moral claims by emphasizing the size and vulnerability of the global youth population. ${ }^{9}$

The IPCC report highlights that climate change is already happening and is exacerbating existing inequalities, with already vulnerable youth being particularly affected. As youth we have the most at stake, therefore we feel we should have a voice on any policies and programs that impact our future (YOUNGO Plenary Intervention).

This reliance on the Cognitive Power of others (such as IPCC scientists) suggests that youth do not perceive their own unique knowledge and experiences to be valued/valuable. Their decision to draw upon Symbolic Power to request additional participatory opportunities also suggests that they do not perceive this mode of participation to be meaningful. This is based on the belief that plenary interventions offer little opportunity to gain agency, as this focus group participant explained:

Interventions show our interest but Parties don't listen. The format isn't interactive, they don't even listen to each other's and ours are at the end when everyone has left.

As a result, only a third of focus group participants and interviewees ${ }^{10}$ had contributed to YOUNGO interventions, with the majority forgoing this participatory opportunity.

Only two negotiators interviewed had heard YOUNGO interventions at SB40. ${ }^{11}$ One, as the meeting Chair could not leave early ${ }^{12}$ the other had made special effort to stay, indicating recognition of YOUNGO's Cognitive Power:

They only got two minutes. Most delegates just left. I sat and listened and heard them talk about adaptation, mitigation, participation and gender (Interview A4).

\footnotetext{
9 Participant Observations; Interviews: E1; E2.

10 Interviews: D1; D3.

11 Interviews: A4; B2.

12 Participant Observation.
} 
Several negotiators said they found some interventions too negative, indicating that Symbolic and Accountability Powers may not be the most efficient way to gain recognition ${ }^{13}$ :

Sometimes youth can be too aggressive, they should push the limits creatively, not just say you need to think about the future. Sometimes we find that arrogant. We have children too; of course we care about the future (Interview B8).

When I see youth taking biased positions I think they don't understand well enough. They should stay away from blaming (Interview B7).

An IGO interviewee (C1) commented that interventions are later shared with Parties, though even the more sympathetic negotiators said it was uncommon for Parties to discuss them. ${ }^{14}$

\subsection{High-level meetings}

The UNFCCC Secretariat facilitates meetings between YOUNGO and high-level officials such as the Subsidiary Body Co-Chairs and Executive Secretary, offering YOUNGO an intimate space to talk to influential individuals. ${ }^{15}$ Preparation is managed online to permit non-attendees to contribute, which YOUNGOs feel increases their Representative Power. Some perceive this as a way to develop Leverage Power by gaining key allies ${ }^{16}$ while others attempt to use Symbolic Power, making moral and representative claims about their constituency to put pressure on high-level decision-makers. ${ }^{17}$

During a High-Level meeting at SB40, YOUNGO were permitted to ask three questions, submitted to the Secretariat for advance approval ${ }^{18}$ (though no submitted questions were rejected). There were high levels of online participation in preparation for this meeting, indicating that youth perceive these interactions as offering significant potential for agency. However, this led to internal friction with much debate over which questions to submit. Some wanted to wield Symbolic and Accountability Power, claiming the moral high ground and questioning the Executive Secretary's allegiance following her attendance at a recent coal summit. Others disagreed, afraid that this may cost them a powerful ally, reducing their Leverage Power. ${ }^{19}$ This led to the eventual submission of weak questions which all could agree upon, paralleling the negotiations themselves. ${ }^{20}$ There is a danger that internal friction will decrease the agency of individuals who choose non-participation over conflict and through lost time spent on internal debate and missed opportunities to gain high-level allies.

High-level decision-makers were unavailable for interview, so whether this combination of Leverage, Symbolic and Accountability Powers can be successfully wielded in this way is unknown. However, based on personal observation of multiple interactions between high-level decision-makers and YOUNGO over several years, it is the author's belief that utilizing Cognitive Power to present concrete, policy-relevant solutions is more positively received than attempts to claim moral superiority, and more likely to lead to the facilitation of subsequent meetings of this nature.

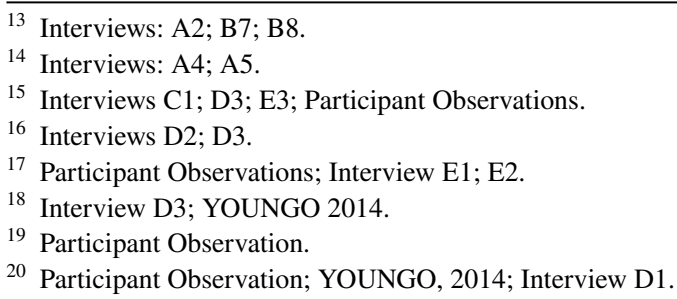




\subsection{Actions}

YOUNGOs perform demonstrations known as 'actions' in the negotiation corridors, designed to attract negotiator and media attention. ${ }^{21}$ Actions require Material Power for resources, though YOUNGO strives for high impact on a low budget, ${ }^{22}$ capturing actions on camera to share through social media, subsidizing their limited Material Power with their ample Social Power. YOUNGO often also draws upon Cognitive Power in actions, presenting policy-relevant information in a novel and entertaining format which is often linked to popular culture. At SB40, a youth-led action involved negotiators jumping across pieces of paper labeled with targets which youth would like to see included in Intended Nationally Determined Contributions (INDCS) which was loosely themed around the Game of Thrones TV series.

During SB40, YOUNGO also supported an ENGO-led action symbolizing a return to the negotiations following a 'walk-out' from the previous COP in Warsaw. ${ }^{23}$ This was an attempt at exercising Representative Power, raising moral concerns that sponsorship from high-carbon industries (including aviation) was affecting ambition and based on the belief that if NSA's were seen to leave, the COP would lose legitimacy. ${ }^{24}$ NSAs made use of their perceived role as 'watchdogs' to question the legitimacy of the COP in the eyes of the public, capturing media attention with their mass walk-out. ${ }^{25}$ Their departure was not permanent, labeled: 'Volveremos' loosely translating from Spanish as 'we will return stronger.' NSAs returned at SB40, holding the logos of many NGOs worldwide to try to maximize their Representative Power, though in reality, geographical diversity was low due to lack of Global South NSA attendance at Intersessionals.

Actions must be requested $24 \mathrm{~h}$ in advance (participant observation), must refrain from personal attacks and should not name individual countries or disrespect their flags (UNFCCC 2017). Infringement of these rules can lead to loss of accreditation. ${ }^{26}$ Many actions are framed positively, but negativity breeds when NSAs perceive they cannot affect the process in another way. ${ }^{27}$ Focus Group participants highlighted several concerns:

I would prefer not to do that type of thing; I would rather talk to people directly.

I don't think they help at all but what else can we do?

When youth perceived that negotiators would not listen to them they resorted to negatively framed actions, drawing upon their Social and Representative Powers to make moral claims, amplified by the media. At SB44, several youth perceived that their agency was negatively affected by business NGOs (BINGO). ${ }^{28}$ This provoked some to engage in 'civil disobedience' (Interview E1). Youth who see their agency as weak treat their participation as a battle ${ }^{29}$ strategically disrupting the negotiations to challenge procedural legitimacy:

We needed to do something drastic. There is a system problem. This is a flawed process (Interview E1).

\footnotetext{
${ }^{21}$ Focus Group; Interviews: D2; E1; E2; E3.

22 Interview E3, Participant Observations.

${ }^{23}$ Participant Observation; Interviews E1; E2; Focus Group.

${ }^{24}$ Interview E1.

25 Interviews E1, E2.

${ }^{26}$ Interviews E2.

${ }^{27}$ Interview E1; Focus Group.

${ }^{28}$ Interviews E1, E2; Participant Observation; Focus Group.

29 Interview E1; E2.
} 
One of the reasons why civil society and youth walked out was because of massive corporate lobbying. We ...can't collaborate with actors who are on a path to destroy our future (Participant Observation).

Many YOUNGOs spent large amounts of time attending preparation meetings and creating paper windmills to hand out during this action. ${ }^{30}$ However, their input to content was limited:

I don't know who organized it. Presumably some of the big ENGOs, I don't know if youth had any input to the messaging or method, all we were asked was how it could be catchy (Interview E1).

No members of ENGO were interviewed, though this indicates that YOUNGO lacks recognition from other constituencies for their Cognitive Power, though their Social Power is valued and utilized. YOUNGOs resort to disruptive strategies (in this case, vocal nonparticipation) as a last resort when they perceive that they lack opportunities to gain agency through facilitated modes of participation. This is a risk as it could lead to loss of accreditation. Additionally, while collaboration with other constituencies could enable knowledge exchange and resource sharing, it could erode youth agency if larger constituencies draw upon YOUNGO's resources without incorporating their views.

Most non-youth interviewees had noticed YOUNGO actions but were unable to recall the content. ${ }^{31}$ This was also the case for 'Volveremos' as seen in this conversation with a negotiator $^{32}$ :

Researcher: Did you see the action this morning?

Negotiator: Yes, what was it about? I just walked through; I don't have time to look at their faces.

An IGO representative had a similar response:

Researcher: Did you see the action this morning?

IGO: No, what was it about?

Researcher: The walk-out from Warsaw

IGO: Oh yeah, they came back the next day when they realized no-one noticed.

Researcher: They came back today

IGO: Haven't they been here anyway?

This indicates that attempts to engage in strategies of disruption or non-participation can easily be overlooked and, while they may challenge perceptions of procedural legitimacy in the eyes of the media, this may go unnoticed by decision-makers inside the process. This is particularly likely when other NSAs remain engaged in the negotiations, diverting attention away from those who have chosen to withdraw.

In contrast, actions expressing Cognitive Power were more successful. A Global South negotiator highlighted that some actions helped him to understand aspects of negotiations which he did not follow personally. He stated that under limited capacity, actions draw

\footnotetext{
${ }^{30}$ Interview E1, Focus Group.

31 Interviews: A3; A6; B2; B4; B5; B6; B7.

32 Interview B7.
} 
attention to important issues. He recalled all of the messages from a YOUNGO action at SB40, stating:

When you see a message it prompts more thoughts. I will share these thoughts with my delegation. The messages from youth help us, we treasure them (Interview A5).

His Head of Delegation later voiced the same sentiment, confirming that the negotiator had indeed shared YOUNGOs policy recommendations. ${ }^{33}$ This suggests that actions can be perceived positively and negatively, depending upon the power sources they draw upon and the strategies they employ. This example highlights that when NSAs gain recognition from one decision-maker, with effective use of Cognitive Power they may indirectly influence others.

\subsection{Side-events and exhibits}

YOUNGOs can attend and host side-events and exhibits. While these do not feed directly into negotiations, they often share policy-relevant information and enable participants to increase their Social and Cognitive Powers through networking and narrative building. Youth recognize their potential to influence other attendees and gain media attention. ${ }^{34}$ However, hosting side-events and exhibits requires Social and Cognitive Power to attract attendees/visitors and sufficient Material Power to prepare, transport and display resources. Sufficient certainty of ones own participation is also needed ahead of side-event and exhibit application deadlines, certainty which is difficult to attain for young volunteers who may have to self-fundraise and request time off from their work and studies to attend.

The young people who participated in this study saw side-event attendance as valuable for their learning. However, only one YOUNGO side-event and one exhibit were hosted at SB40, both by the United Nations of Youth Network, with a focus on forest management education (UNFCCC 2014b). YOUNGOs recognize side-events and exhibits as opportunities for agency but often lack capacity to apply and plan for them in advance, though they may gain speaking opportunities during events organized by other actors. ${ }^{35}$ As such, it is apparent that a level of Material Power is required in order to fully utilize these modes of participation which is more advantageous to better-resourced NSAs.

No non-youth interviewees had attended YOUNGO's side-event or exhibit at SB40. Only the negotiators and IGO representative working on Article 6 had ever attended a YOUNGO side-event or exhibit. ${ }^{36}$ Some claimed they were willing but lacked the time. ${ }^{37}$ Others just did not see it as a priority, ${ }^{38}$ indicating a lack of recognition of YOUNGO's Cognitive Power outside of Article 6 policy.

\subsection{Summary of results}

See Table 2.

\footnotetext{
33 Interview B1.

34 Participant Observation; Interviews D2; E3.

35 Focus Group; Participant Observations.

${ }^{36}$ Interviews: A1; A2; A3; A4; A5; C1; C2; C3.

37 Interviews: B2; B6.

38 Interviews: B4; B7.
} 
Table 2 YOUNGO agency across UNFCCC modes of participation

Conference access

Plenary interventions

High-level meetings

Actions

Side-events and exhibits Young people perceive that side-events and exhibits offer potential to increase their agency. However, hosting these modes of participation requires material resources which youth struggle to muster. As volunteers, young people, often struggling to fund their own attendance, are unlikely to be able to commit to participation sufficiently far in advance to meet UNFCCC deadlines for sideevent and exhibit applications. As a result, youth-led side-events and exhibits are limited in number and the potential to utilize this mode of participation remains largely unrealized.

\section{Discussion}

In response to Michele Betsill's (2008) call for research into the relationship between NSA strategy selection and influence, this study finds that young people select between participatory strategies and draw upon certain power sources (Nasiritousi et al. 2016) in response to the level of agency which they perceive to be available.

When youth perceive that they have recognition and can thus expect to be listened to, they draw upon their Cognitive and Social Powers to offer concrete policy suggestions. These are generally well-received, indicating that youth can gain agency within the 
UNFCCC, as seen in the Article 6 negotiations. However, when youth perceive that their potential for agency is low, it is often based on their interpretation of a structural barrier (which may or may not be unique to their constituency, such as the timing of plenary interventions) as being indicative of a lack of recognition that they are relevant actors within the process. This often results in youth trying to claim recognition rather than directly pursuing agency. They do this by emphasizing their vulnerability, their links to future generations and the large and growing global youth population which they nominally represent. Appealing to their Symbolic Power through moral and representative claims is a popular strategy, but alter perceptions suggest that it does not always lead to agency. This may be due to the relative privilege of UNFCCC youth participants, whose vulnerability and representativeness is subject to debate, or because this strategy does not produce concrete, politically feasible solution for policy-makers to utilize within the structural constraints of the UNFCCC.

From the alter interviewees' perspective, while there was some acknowledgement of YOUNGO's Symbolic Power, several interviewees expressed annoyance at youth for utilizing the speaking opportunities they are given to reiterate why they should be heard, rather than proposing tangible suggestions for policy-makers to act upon. This leads to diminished recognition of the role which youth can play, which in turn leads youth to believe that their participation is tokenistic. As a result, youth then resort to disruptive strategies, attempting to wield their Social, Material and Leverage Powers in order to challenge the legitimacy of the UNFCCC process and the state actors within it. This negatively impacts upon their agency as it damages how they are perceived by decision-makers, creating a downward spiral of low self-perception, negative participatory strategies and loss of recognition. Conversely, when youth perceive their agency to be high they demonstrate their Cognitive and Social Powers with direct, constructive interactions. This has been critical for youth in gaining recognition, leading to agency in the Article 6 negotiations, and demonstrates that there is a cyclical relationship between ego perceptions of agency, selection of power sources and strategies, recognition from decision-makers and NSA transitions from actors to agents.

The modes of participation which the UNFCCC Secretariat facilitates do not increase NSA agency unless recognition has already been secured. Without recognition, decisionmakers, under time and resource constraints, are unlikely to pay attention to YOUNGO as they do not recognize the value in doing so. This is potentially relevant to all UNFCCC constituencies, particularly those with fewer resources who must make strategic decisions on how best to mobilize their limited Material Power. The young participants of this study referred to many of the activities identified by Schroeder and Lovell (2012), with the exception of written submissions and press conferences which they did not mention, perhaps because these require a level of capacity which they did not possess at the time of data collection. Their many references to 'actions' builds upon Schroeder and Lovell's brief mention of 'protests' and demonstrate that this is a particularly important mode of participation for young people, in spite of mixed perceptions regarding the utility of this participatory strategy.

With the exception of Material Power which they recognize their lack of, youth are quick to attribute challenging participatory experiences to lack of recognition rather than to lack of power sources. Lack of Material Power compromises their ability to utilize certain modes of participation to their full advantage, distinguishing the participatory experiences of youth from that of other groups. This suggests that, although facilitated modes of participation can help young participants to navigate the complex UNFCCC process by 
providing structured entry points, modes which require a certain level of Material Resource may privilege certain actors.

In contrast to previous studies (Schroeder and Lovell 2012; Hjerpe and Linnér 2010; Hjerpe and Buhr 2014), side-events were less well-utilized by YOUNGO, in spite of acknowledgement from youth that they offer significant potential for knowledge exchange, networking, recognition and issue framing. This study therefore adds further evidence in support of Hjerpe and Linnér's challenge to the notion that side-events enhance pluralism and thus improve procedural legitimacy in the UNFCCC. Schroeder and Lovell's (2012) suggestion of broadening engagement through virtual conferencing and encouraging cohosting of side-events to bring together diverse actors could support young people to overcome these barriers to their agency.

Lack of Material Power also limits the ability of young volunteers to sustain participation over time. This makes it difficult to develop relationships with negotiators, meaning that the 'insider status' enjoyed by other NSAs (Betsill and Corell 2008) is more difficult to attain. This puts less-established NSAs at a disadvantage, particularly when observer access is heavily restricted, as seems to reoccur at critical moments such as the Kyoto Protocol negotiations (ibid); COP 15 (Schroeder and Lovell 2012) and COP 21 (Lövbrand et al. 2017).

Findings also support Albin (1999), by demonstrating that in spite of having equal access to the intergovernmental space, powerful groups remain dominant, as seen in YOUNGO's relationship with ENGO. Although collaboration could increase their Material and Social Powers, YOUNGO and other small constituencies should remain mindful of their own objectives and preferred strategies to ensure that their Cognitive Power is not overlooked when working with other NSAs.

In answer to Michele Betsill's (2008) call for further research into whether the nature of an issue has implications for NSA agency, this paper provides empirical evidence that certain issues are more open to NSA agency such as Article 6 where youth are deemed to have relevant expertise. However, results show that recognition is constrained by the silos in which policies are negotiated. This contributes a more nuanced understanding of Nasiritousi et al's (2016) identification of the Governance Profiles attributed to each UNFCCC constituency, raising important considerations for procedural legitimacy and justice.

\section{Conclusion}

This paper sheds light upon YOUNGO as a previously un-researched TAN and provides insight into the structure and agency of this constituency. It tests and develops the power source concept (Nasiritousi et al. 2016) and finds that while NSA transitions from actor to agent depend upon recognition of their governance profiles, this is also shaped by the strategies which NSAs employ. It also finds that agency is often limited to the policy silos in which recognition is negotiated rather than spanning all aspects of global environmental governance as previously assumed.

By cooperating as a TAN, youth have gained recognition from the UNFCCC Secretariat in the form of constituency status, based largely on their Representative Power. However, within the intergovernmental process, it is their Social and Cognitive Powers which appear to be most successful in securing recognition. These appear to be best wielded with constructive, targeted strategies which focus on building relationships with individual decision-makers and offering concrete, policy-relevant and politically feasible solutions. 
However, this is particularly difficult for YOUNGO on account of their lack of Material Power which hinders their ability to sustain participation and to develop relationships over the longer-term. In the hubbub of UNFCCC negotiations, where decision-makers have limited time and capacity they are unlikely to attend youth events or to seek out their advocacy messages unless they already perceive them to be valuable contributors. This paper has demonstrated that the participatory experiences which young people undergo in the UNFCCC shape and are shaped by their perceptions of the process and their agency within it. When young people believe that their input is welcome they are encouraged to engage in a way which aligns with procedural norms and is resultantly well-received. However, when their participatory experiences are negative, youth attribute this to lack of recognition rather than to structural barriers or to their lack of a particular Power Source. This fosters a perception of marginalization, catalyzing a chain of more combative participatory activities. It therefore becomes apparent that if the UNFCCC wishes for youth to remain engaged in the UNFCCC as constructive rather than disruptive actors, they should invest in ensuring that the early experiences of new participants are positive ones, and that participatory arrangements take account of the differentiated abilities of NSAs to utilize them, paying particular attention to those endowed with less Material Power.

As global environmental change looms large, NSA involvement is considered ever more important in creating legitimacy for environmental policy and supporting implementation, as emphasized in the Paris Agreement. It is therefore pertinent to assess whether the modes of NSA participation facilitated within intergovernmental processes actually foster agency, for whom, and under which circumstances. It is also necessary to determine the Governance Profiles of different NSA groups to ensure that limited resources are strategically deployed. Further research should assess the extent to which these findings are applicable to other policy fora, with specific focus on the youth who will inherit these governance challenges and whose agency is therefore critical to the longevity of environmental policy. As one interviewee expressed:

As the youth population is growing worldwide, those Parties who involve youth upfront will have a head start. ${ }^{39}$

Acknowledgements An enormous thank you to Stavros Afionis for your unfailingly enthusiastic and invaluable support and to Lucie Middlemiss and Philippa Roddis for bringing fresh insights to this paper.

\section{Compliance with ethical standards}

Conflict of interest The author declares that they have no conflict of interest.

Open Access This article is distributed under the terms of the Creative Commons Attribution 4.0 International License (http://creativecommons.org/licenses/by/4.0/), which permits unrestricted use, distribution, and reproduction in any medium, provided you give appropriate credit to the original author(s) and the source, provide a link to the Creative Commons license, and indicate if changes were made.

39 Interview $\mathrm{C} 1$. 


\section{References}

Albin, C. (1999). Can NGOs enhance the effectiveness of international negotiation? International Negotiation, 4(3), 371-387.

Arts, B. (1998). The political influence of global NGOs: Case studies on the climate and biodiversity conventions. Utrecht: Jan van Arkel (International Books).

Betsill, M. M. (2008). Environmental NGOs and the Kyoto Protocol negotiations: 1995 to 1997. In M. M. Betsill (Ed.), NGO diplomacy: The influence of nongovernmental organizations in international environmental negotiations (pp. 43-66). Cambridge: MIT Press.

Betsill, M. M., \& Corell, E. (2008). NGO diplomacy: The influence of nongovernmental organizations in international environmental negotiations. Cambridge: Mit Press.

Boström, M., \& Hallström, K. T. (2010). NGO power in global social and environmental standard-setting. Global Environmental Politics, 10(4), 36-59.

Bulkeley, H., \& Newell, P. (2015). Governing climate change. Abingdon: Routledge.

Charmaz, K. (2014). Constructing grounded theory. Thousand Oaks: Sage.

Dellas, E., Pattberg, P., \& Betsill, M. (2011). Agency in earth system governance: Refining a research agenda. International Environmental Agreements: Politics, Law and Economics, 11(1), 85-98.

Gulbrandsen, L. H., \& Andresen, S. (2004). NGO influence in the implementation of the Kyoto Protocol: Compliance, flexibility mechanisms, and sinks. Global Environmental Politics, 4(4), 54-75.

Hanegraaff, M. (2015). Transnational advocacy over time: Business and NGO mobilization at UN climate summits. Global Environmental Politics, 15, 83-104.

Hjerpe, M., \& Buhr, K. (2014). Frames of climate change in side events from Kyoto to Durban. Global Environmental Politics, 14(2), 102-121.

Hjerpe, M., \& Linnér, B.-O. (2010). Functions of COP side-events in climate-change governance. Climate Policy, 10(2), 167-180.

Jordan, A. J., Huitema, D., Hildén, M., Van Asselt, H., Rayner, T. J., Schoenefeld, J. J., et al. (2015). Emergence of polycentric climate governance and its future prospects. Nature Climate Change, 5, 977.

Keck, M. E., \& SIKKINK, K. (1999). Transnational advocacy networks in international and regional politics. International Social Science Journal, 51(159), 89-101.

Lövbrand, E., Hjerpe, M., \& Linnér, B.-O. (2017). Making climate governance global: How UN climate summitry comes to matter in a complex climate regime. Environmental Politics, 26(4), 580-599.

Nasiritousi, N., Hjerpe, M., \& Linnér, B.-O. (2016). The roles of non-state actors in climate change governance: Understanding agency through governance profiles. International Environmental Agreements: Politics, Law and Economics, 16(1), 109-126.

Rodrigues, M. G. M. (2003). Global environmentalism and local politics: Transnational advocacy networks in Brazil, Ecuador, and India. Albany: SUNY Press.

Schroeder, H. (2010). Agency in international climate negotiations: The case of indigenous peoples and avoided deforestation. International Environmental Agreements: Politics, Law and Economics, 10(4), 317-332.

Schroeder, H., \& Lovell, H. (2012). The role of non-nation-state actors and side events in the international climate negotiations. Climate Policy, 12(1), 23-37.

Steffek, J., \& Nanz, P. (2008). Emergent patterns of civil society participation in global and European governance. In P. Nanz \& J. Steffek (Eds.), Civil society participation in European and global governance (pp. 1-29). New York: Springer.

UNCED (United Nations Conference on Environment and Development). (1992). Agenda 21: programme of action for sustainable development; Rio Declaration on Environment and Development; the final text of agreements negotiated by governments at the United Nations Conference on Environment and Development (UNCED), 3-14 June 1992. Rio de Janeiro, Brazil. [online]. [Accessed 10 June 2016]. https://sustainabledevelopment.un.org/content/documents/Agenda21.pdf.

UNFCCC. (2010). Youth participation in the UNFCCC negotiation process: The United Nations, young people, and climate change, a publication of the united nations joint framework initiative on children, youth and climate change [online]. [Accessed 21 June]. http://unfccc.int/files/conference_programme/ application/pdf/unfccc_youthparticipation.pdf.

UNFCCC. (2014a). Accredited observer organizations [online]. [Accessed 21 June]. http://unfccc.int/parti es_and_observers/ngo/items/9411.php.

UNFCCC. (2014b). Side events/exhibits archive [online]. [Accessed 21 June 2015]. https://seors.unfccc.int/ seors/reports/archive.html.

UNFCCC. (2015). Paris agreement [online]. [Accessed 30 July 2016]. http://unfccc.int/paris_agreement/ items/9485.php. 
UNFCCC (United Nations Framework Convention on Climate Change). (2017). [online]. [Accessed 21 Feb 2018]. https://unfccc.int/files/parties_and_observers/ngo/application/pdf/coc_guide.pdf.

United Nations. (2012). The future we want. In United Nations conference on sustainable development, 20-22 June 2012, Rio de Janeiro.

Vormedal, I. (2008). The influence of business and industry NGOs in the negotiation of the Kyoto mechanisms: the case of carbon capture and storage in the CDM. Global Environmental Politics, 8(4), 36-65. 